\title{
The Sociology of Language Teaching and Learning
}

\author{
Ravi Bhushan \\ Department of English, BPS Mahila Vishwavidyalaya, Khanpur Kalan (Sonipat), Haryana, India \\ Email: bhushanravi_sharma@yahoo.co.in
}

\begin{abstract}
Any language must be treated in a social context. For a language teacher, it is important to relate language to society, because languages are taught and learnt to establish contact and communication across language boundaries. In fact society and culture are more than background and context. They both represent people with whom the learners eventually must make contact if language learning is to have any value in human terms. Language teaching can be looked upon as a deliberate intervention into ethno-linguistic relations which can be planned more or less effectively and which can contribute to the bilingualism of a society. Socio- cultural factors that affect motivation, such as the relative social status of the first language and the second language, the instrumental value of the second language, the cultural value of the second language and political factors should be considered. Sociolinguistics and other social sciences have a major role to play in second language pedagogy, profoundly influencing the quality of language programmes and provision of language in a speech community. The scope of this paper is to ascertain the role of social scientists, educational linguists, and language teachers who must come together to facilitate better teaching and learning of language.
\end{abstract}

Index Terms-sociolinguistics, linguistic competence, communicative competence, culture

The language teachers did not wait for sociolinguistics to come along in order to realize the relationship between language, culture and society. Language teachers and linguists have faced the common question of overemphasizing either the linguistic forms or people and countries. If they emphasize linguistic forms and neglect the people who use the forms in ordinary communication, the basic purpose of using the language is distorted. If they emphasize people and country and neglect linguistic forms, teaching becomes superficial and ineffective. In fact language teachers have been teaching language as a purely formal system. They forget that their students need to contact with native speakers and that a language class should create an introduction to a country and its people.

Language cannot be taught without coming face to face with social context factors which have significant impact on language teaching and learning. Language and society are closely linked. Comparing human and non-human societies, it has been observed that, "it is this inability to produce language...that keeps the apes as they are. For culture is only transmissible through coding, classifying and concentrating experience through some form of language. A developed language therefore is a unique and distinctive human trait..." (Worslay, 1970, p.25). The language learner should not only study the cultural context but he/she should also be made aware of the interaction between language and culture. The British anthropologist cum linguist Malinowski says, "Language is essentially rooted in the reality of the culture, the tribal life and customs of the people, and...it cannot be explained without constant reference to these broader contexts of verbal utterance" (1923, p.305). He further says that 'an utterance becomes only intelligible when it is placed within its contexts of situation..." (op.cit. 306).

According to William Labov, the chief exponent of sociolinguistics, the study of language within the context of a speech community is linguistics. While studying the common topics of linguistic analysis, phonology, morphology, syntax, discourse analysis, semantics etc in their pure and abstract form, leaves out the most interesting; the infinite varieties of language use. He says that "the basic data for any form of general linguistics would be language as it is used by native speakers communicating with each other in everyday life" $(1971$, p. 153). The mode for the analysis of languages has shifted from the utterance in isolation and the study of a context into which this utterance must be placed towards an attempt to regard the interpersonal social act as the primary event and the speech forms as secondary. The act of communication is not seen as an exchange of linguistic messages, but rather as a socially meaningful episode. Let us take an example of two friends A and B.

A (waving his hand) to B: How are you?

B: How am I in regard to what? Health, finance, school, work or peace of mind?

A (angrily): Look! I was just trying to be polite. Frankly, I do not care how you are?

The concept of 'Communicative Competence' is widely accepted in language pedagogy. It is "a competence of when to speak, when not, and as to what to talk about with whom, when, where, in what manner" (Hymes, 1972, p. 277). This concept definitely challenged Chomsky's 'linguistic competence' which is confined to internalized rules of syntax and abstracts from the social rules of language use. Communicative Competence no doubt implies linguistic competence but its main focus is the grasp of social and cultural rules and meanings that are carried by any utterance. Language teaching must recognize social, interpersonal and cultural dimension as important as grammatical and phonological aspect. 
Language learning in the classroom continues to be conceived as training rather than as real communication or as an introduction to a foreign society. This emphasis on learning of language forms, developing mental associations, and acquiring speech habits or the emphasis on the acquisition of skills, independent of communication in society prevailed until most recent times and in many ways is still dominant today. Language teaching theorists have repeatedly stated that an important purpose of language learning is to learn about a country and its people. A widely read book during World War I recommended "some knowledge of the history of the people who speak the languages" as a necessary part of the language programme (Atkins and Hutton, 1920, p. 247).

The treatment of culture in language programmes concentrates on non- linguistic features. From the point of view of language pedagogy it is important at anytime not to separate too rigidly language from society and culture. In practice, integration of language with its socio-cultural context hasn't been easy. The description of language on which language pedagogy is based is generally 'a-social' and 'culturally neutral' (Stern, 1983, p. 256).

The social context of language learning can be regarded as a set of factors that is likely to exercise a powerful influence on language learning and it is therefore necessary to take note of such contextual factors in analyzing a given language teaching situation. Socio- cultural factors that affect motivation, such as the relative social status of the first language and the second language the instrumental value of the second language, the cultural value of the second language and political factors should be considered.

The question of the relationship between the social milieu and language learning has become particularly acute in recent studies on bilingual education. Paulston (1975) argued 'that we can begin to understand the problems and question of bilingual education only when we see bilingual education as the result of certain societal factors'. In order to study the environmental influences on language, Mackey (1970) developed a typology showing the intricate varieties that may occur when we relate the language of the school to the home, area or nation. Mackey identifies the following nine different ways of arranging the language curriculum in schools leading to no less than ninety different patterns of interaction between home, school, area and nation.

i. The school may be located in a place where neither the language of the area nor the national language is that of the home.

ii. It may be in a country where the language of the home but not that of the area is the national tongue.

iii. The language of the area and not of the nation may be that of the home.

iv. Both are and national language may be that of the home.

v. he national language may not be that of the home but the area may be bilingual, with both the home and national languages being used.

vi. The country may be bilingual and the area unilingual.

vii. Both the area and the country may be bilingual.

viii. The area may be bilingual and the national language may be that of the home.

ix. The county may be bilingual and the area language that of the home.

If we apply Mackey's categories to language teaching in general, it shows how different social variables interact with language teaching and learning.

The most obvious contextual factor against which to view language learning is the language situation. Some countries are linguistically homogeneous e.g. Germany, France, Britain, Argentina or Thailand. In these countries language learning takes place against a fairly uniform language background and students are likely to have many language learning problems in common. Moreover a uniform language environment creates among students the illusion of universal unilinguality which can lead to resistance to second language learning. Heterogeneous language situations are much more complex. For example, learning English in India as a second language has to face a sociolinguistic context of many languages and dialects.

This has the advantage that students approach language learning on the basis of experience with different languages and varied language contacts in their own environment, but the diversity of language backgrounds in the language class may complicate the teaching task. Another linguistic aspect to bear in mind is the learner's language. The linguistic and cultural distance between the first and second language suggest some learning problems. Most of the European languages such as English, French, German, Russian, Italian and Spanish share common European linguistic and cultural assumptions, reflected in the vocabulary and grammar of these languages. Equally many of the languages in India like Hindi, Gujrati have much in common. A European learning an oriental language such as Chinese, Japanese, and Hindi faces many unfamiliar linguistic and cultural factors. Similarly, a native speaker of Hindi or Japanese faces similar problems in learning English as a second language. Linguistic similarity is no absolute guarantee that the second language will be easily learnt. Other factors may be more important than linguistic similarities.

Socio-cultural factors are closely associated with the language situations. They are, the social organization of the community and different groups that constitute the society, its social and occupational classes, ethnic, cultural and religious groups. Socio-economic and socio-cultural differences are equally important. Particular languages are sometimes held in either high or low esteem because of economic, political or cultural values associated with them. Students therefore frequently come to language learning with positive or negative attitudes derived from the society in which they live and these attitudes influence their motivation to learn the second language. However the relationship 
between socio economic or socio-cultural factors and language learning can't be treated as self evident. At times this relationship is far less evident.

The geographical distance between linguistic communities may have some bearing on language learning. The geography of the situation must not be interpreted too mechanically. Ease of communication has served to overcome geographical distance to some effect; but in spite of that, it makes a difference whether a second language is used within or close to the environment in which the language is learnt or is one available at increasing distances from it. The distinction that is often made between second language and foreign language is primarily a distinction between the geographical settings in which the language is used and the socio-linguistic and socio-cultural implications of these settings for language teaching and learning. In the second language situation where the language is used within the environment in which it is learnt, teachers and learners have immediate and regular access to opportunities of language use. In the First Language situation the environment support is lacking and therefore has to be compensated for by special pedagogical measures.

In general, it is probably less the geographical distance as such that affects learning than how the language is perceived by teachers and learners. In assessing a language teaching situation it is important to ask whether the second language is available within the learning environment or if not at what distance from the learning environment it is.

Economic and technological factors are important as far as language teaching and learning are concerned. The acquisition of technological skill depends upon the knowledge of a major world language through which these skills may be acquired. Thus, in the third world countries English as a second language is a pre-requisite to scientific or technological training. Language learning demands an economic investment and a society may have to weigh up the importance of language learning against the importance of other educational needs. Language teaching in advanced industrialized societies has been characterized by abundance of teaching materials and of electronic audio and video equipment. Many developing countries lack such materials or equipment and can't afford to buy them. They may also lack the skilled manpower to install and maintain such equipment. It is therefore important for an analysis of the context of language teachers to take account of economic and technical capabilities in determining curriculum materials or in recommending techniques or a technology. Most of the developing countries may be interested in a simple technology of second language learning than in costly gadgets because of economy and shortage of technological skill to service equipment.

In the realm of language teaching and learning, social context is very important. In fact language itself must be treated in a social context. It is very important to relate language to society, because languages are taught and learnt to establish contact and communication across language boundaries. Society and culture are more than background and context. They represent people with whom the learner eventually must make contact. Language teaching can be viewed as a deliberate intervention into ethno linguistic relations which can be planned more or less effectively and which ultimately contribute to the bilingualism of a society. Sociolinguistics and other social sciences have major role to play in second language pedagogy, influencing the quality of language programmes and the provision of languages in a speech community. The relationship between the social sciences and language pedagogy has developed differently from that between linguistics and language teaching. Social scientists unlike linguists have been indifferent to language pedagogy and have hardly recognized the importance of theories and descriptions of society and culture for language teaching. In the long run the best hope for the future lies in cooperation between social scientists, educational linguists and language teachers.

\section{REFERENCES}

[1] Atkins, H.G. and Hutton, H.L. (1920). The teaching of modern foreign languages in school and university. London: Arnold.

[2] Hymes, D. (1972). 'On communicative competence' in Pride and Holmes, 269-93.

[3] Labov, W. (1971). 'The study of language in its social context' in Fishman, 152-216.

[4] Mackey, W.F. (1970). A typology of bilingual education. Foreign Language Annals 3:596-608.

[5] Malinowski, B. (1923). 'The problem of meaning in primitive languages' in Ogden and Richards, 451-510.

[6] Paulston, C.B. (1975). Ethnic relations and bilingual education: accounting for contradictory data. Working Papers on Bilingualism 6:1-44.

[7] Stern, H.H. (1983). Fundamental concepts of language teaching. Oxford: Oxford University Press.

[8] Worsley, P. et al. (1970). Introducing Sociology. Harmondsworth: Penguin Books.

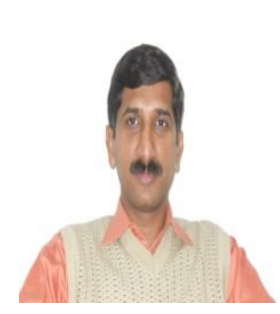

Ravi Bhushan is working as an Assistant Professor of English in Bhagat Phool Singh Women University, Khanpur Kalan (Sonipat), Haryana, India since 2007. Dr Bhushan acquired his PhD degree in English literature from University of Madras in 2001. He has also acquired Post Graduate Certificate Course in Teaching of English (PGCTE) from the English and foreign Languages University, Hyderabad, India. He has presented 19 Research Papers at National and International Conferences and has published 14 Papers and written four books. Dr Bhushan is a recognized Trainer cum Examiner of Cambridge University ESOL Examinations department. Presently he is working on the University Grants Commission, India sponsored Major Research Project on "Status of ELT at primary, secondary and tertiary level in his home State". 